\title{
Tie2 and Eph Receptor Tyrosine Kinase Activation and Signaling
}

\author{
William A. Barton ${ }^{1}$, Annamarie C. Dalton¹, Tom C.M. Seegar ${ }^{1}$, Juha P. Himanen², \\ and Dimitar B. Nikolov ${ }^{2}$ \\ ${ }^{1}$ Department of Biochemistry and Molecular Biology, School of Medicine, Virginia Commonwealth \\ University, Richmond, Virginia 23298 \\ ${ }^{2}$ Structural Biology Program, Memorial Sloan-Kettering Cancer Center, New York, New York 10065 \\ Correspondence: nikolovd@mskcc.org
}

\begin{abstract}
The Eph and Tie cell surface receptors mediate a variety of signaling events during development and in the adult organism. As other receptor tyrosine kinases, they are activated on binding of extracellular ligands and their catalytic activity is tightly regulated on multiple levels. The Eph and Tie receptors display some unique characteristics, including the requirement of ligand-induced receptor clustering for efficient signaling. Interestingly, both Ephs and Ties can mediate different, even opposite, biological effects depending on the specific ligand eliciting the response and on the cellular context. Here we discuss the structural features of these receptors, their interactions with various ligands, as well as functional implications for downstream signaling initiation. The Eph/ephrin structures are already well reviewed and we only provide a brief overview on the initial binding events. We go into more detail discussing the Tie-angiopoietin structures and recognition.
\end{abstract}

\section{ANGIOPOIETINS AND TIE2}

$V^{2}$ asculogenesis and angiogenesis are distinct cellular processes essential to the creation of the adult vasculature. In early embryonic development, precursor angioblasts differentiate into endothelial cells, migrate, and form the vasculature framework including major primitive blood vessels and the endocardium of the developing heart. This process, known as vasculogenesis, results in a poorly branched and loosely connected capillary plexus. Angiogenesis further remodels the primitive endothelial network into a highly branched microvasculature and results in the intussusception of vessels into some organs (Adams and Alitalo 2007; Huang et al. 2010).
In contrast to vasculogenesis, angiogenesis is continually required in the adult for wound repair and remodeling of reproductive tissues during female menstruation. Importantly, pathological angiogenesis aids solid tumor growth by providing an enriched nutrient and oxygen supply, as well as a mechanism for tumor cell dissemination (metastasis). Thus, understanding the role of receptors and ligands that control angiogenesis is essential for shaping a fundamental understanding of tumor development (Adams and Alitalo 2007; Huang et al. 2010).

Two major endothelial receptor tyrosine kinase signaling pathways are essential for angiogenesis: these include the vascular endothelial growth factor (VEGF) receptor and the Tie2

Editors: Joseph Schlessinger and Mark A. Lemmon

Additional Perspectives on Signaling by Receptor Tyrosine Kinases available at www.cshperspectives.org

Copyright (C) 2014 Cold Spring Harbor Laboratory Press; all rights reserved; doi: 10.1101/cshperspect.a009142

Cite this article as Cold Spring Harb Perspect Biol 2014;6:a009142 
W.A. Barton et al.

receptor. Whereas VEGF appears to function as a general regulator of vasculogenesis and angiogenesis, the Ang-Tie system plays a role downstream of VEGF signaling during angiogenesis. Since the initial discovery of the Tie receptors in 1992, a stream of studies have slowly illuminated the role of this signaling pathway in angiogenesis, particularly with regard to its role in the communication between support cells and endothelium (Adams and Alitalo 2007; Huang et al. 2010). However, despite significant molecular developments, high-resolution structural information has only recently become available. Below, we discuss the structural characteristics, and their functional implications, of the unique Tie-angiopoietin signaling system.

\section{Angiopoietin Ligands}

The angiopoietins (Ang1-4) modulate the activity of Tie2. These four secreted protein ligands maintain a high level of sequence homology while eliciting distinct responses from their target receptor (Fig. 1) (Davis et al. 1996, 2003; Maisonpierre et al. 1997; Ramsauer and D'Amore 2002). Although the agonist Ang3 and antagonist Ang4 are poorly characterized (Valenzuela et al. 1999), extensive data establishes Ang1 to be a strict agonist of Tie2 activation, leading to prosurvival signaling and quiescence of the endothelium (Davis et al. 1996; Papapetropoulos et al. 2000). In contrast, Ang2 has been shown to competitively inhibit Ang1 activation, suggesting a single ligand-binding site on Tie2 and an antagonistic role for Ang2 (Maisonpierre et al. 1997; Fiedler et al. 2003). The precise role of Ang2 is actually context-dependent, as dimeric Ang2 is capable of activating Tie2 in fibroblasts stably expressing the endothelial-specific receptor (Davis et al. 2003).

Early studies by Davis et al. $(1996,2003)$ established that Tie2 recognition is predominantly mediated by the angiopoietin conserved carboxy-terminal fibrinogen-like domain (see below); however, it was further shown that the fibrinogen domain alone is not sufficient for activation of the receptor. Instead, activation requires the presence of the central coiled-coil region that enables dimerization of the ligands

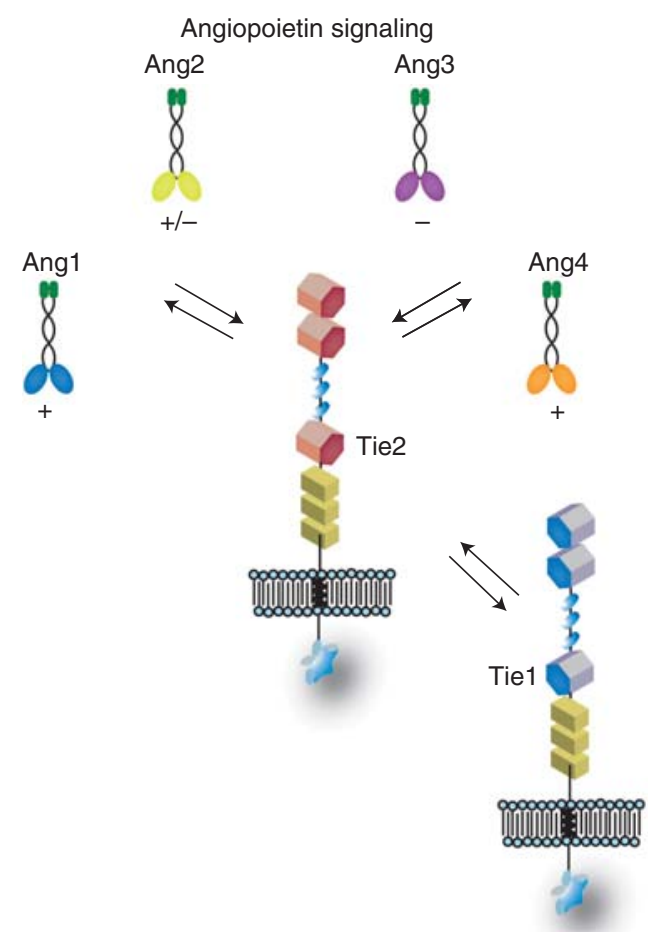

Figure 1. Schematic representation of the Tie receptors and angiopoietin ligands. The Tie receptors are highly homologous endothelial-specific receptor tyrosine kinases. Each receptor consists of three Ig domains (shown in red, green, and blue), three EGF domains (yellow, magenta, orange), and three fibronectin type III repeats (gray) in the ectodomain, followed by a single-pass transmembrane domain, and a split tyrosine kinase domain in the cytoplasm. Tie2 interacts with all four of the structurally similar angiopoietin ligands (Ang1-4), although each ligand is functionally distinct. The angiopoietins contain an amino-terminal super-clustering domain (green), a coiled-coil domain, and a fibrinogen-like receptorbinding domain. Ang1 (blue) and Ang3 (purple) are agonists of Tie2 activation, Ang4 (orange) is an antagonist, and Ang2 (yellow) is a context-dependent antagonist as indicated. Despite the high level of sequence conservation between the two receptors, Tiel is an orphan receptor, yet is able to heterodimerize with Tie2 on the cell surface.

while further higher order homo-, or potentially hetero-, oligomerization can be induced by the amino-terminal "super-clustering" domain (Fig. 1). Indeed, electron micrographs show both Ang1 and Ang2 as dimers, tetramers, and higher-ordermultimers, although Ang 2 has been 
Tie2 and Eph RTK Activation and Signaling

shown to exist primarily as a dimer in solution. Biochemical assays show a requirement for tetrameric Ang1 to elicit endogenous Tie2 activation; however, an engineered dimer may also elicit some receptor activation in fibroblasts exogenously expressing Tie2 (Ward and Dumont 2002; Davis et al. 2003; Fiedler et al. 2003).

Crystal structures of the fibrinogen-like receptor-binding domains (RBDs) of both human Ang1 and Ang2 have been determined at 2.7 and $2.4 \AA$, respectively. Predictably, at $64 \%$ sequence homology, very little structural deviation (rootmean-square deviation [rmsd] of $0.77 \AA$ ) was observed between the compact Ang-RBD structures $(\sim 50 \times 40 \times 35 \AA$ ) (Fig. 2A) (Barton et al. 2005, 2006; Yu et al. 2013). Of the three subdomains, termed $\mathrm{A}, \mathrm{B}$, and $\mathrm{P}$, as per human fibrinogen nomenclature, the $\mathrm{P}$ domain is the least evolutionarily conserved and is solely responsible for the receptor interactions. It contains little secondary structure but is stabilized by a conserved $\mathrm{Ca}^{2+}$-binding site coordinated by two aspartic acid side chains and main chain oxygen atoms (Barton et al. 2005).

An analysis of the hydrophobicity and electrostatic potential of the Ang-RBDs surfaces yields additional details about the functional differences between the angiopoietin ligands. For example, the A and B domains are largely similar and even the P domain, which contains the majority of the significant structural differences between the ligands, contains mostly con- served surface side chains. The only significant difference is within a three amino acid surface loop containing residues 461-463 in Ang2 and residues 463-465 in Ang1 (Fig. 2, left panel). The loop, which varies from T-A-G in Ang1 to P-Q-R in Ang2, shows differences in both hydrophobic and electrostatic properties. Interestingly, functional differences between Ang1 and Ang2 result from alterations in this sequence as a chimeric Ang2 behaves as a receptor agonist (see below) (Yu et al. 2013).

\section{Tie Receptors}

The structurally related Tie 1 and Tie 2 are type 1 transmembrane receptor tyrosine kinases regulating vessel branching and maintaining endothelial homeostasis (Ramsauer and D'Amore 2002). The Tie receptors consist of three immunoglobulin-like (Ig) domains, three epidermal growth factor (EGF) domains, and three fibronectin type III repeats (FNIII) in the extracellular protein segment (Figs. 1 and 2B) (Barton et al.2006; Seegaret al.2010). A single-passtransmembrane domain separates this ectodomain from a structurally conserved split tyrosine kinase domain with homology with fibroblast growth factor receptor (FGFR1) (Shewchuket al. 2000). Despite extensive homology, Tie1 remains an orphan receptor while Tie2 binds all angiopoietin ligands (Davis et al. 1996; Maisonpierre et al. 1997; Valenzuela et al. 1999).
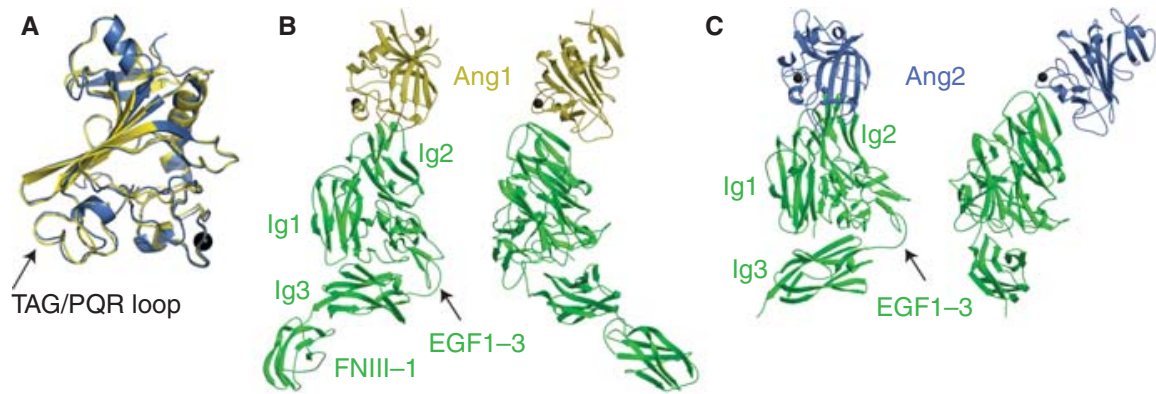

Figure 2. Crystal structures of the angiopoietin receptor binding domains and the Tie2 ectodomain unbound and in complex with Ang1 and Ang2. (A) The Ang1 and Ang2 receptor-binding domains superimposed in blue and yellow, respectively. The calcium ion located within the $\mathrm{P}$ domain is displayed in space-filling representation in black. The surface loop, which mediates Ang1/Ang2 functional differences, is labeled. $(B, C)$ The Ang1-Tie2 and Ang2-Tie2 crystal structures illustrated in two orientations. The Tie 2 receptor is shown in green and its domains are labeled. The Ang1-Tie2 model contains an additional fibronectin type-III repeat not present in the Ang2-Tie2 structure. 
W.A. Barton et al.

The Tie2 ectodomain structure was studied by X-ray crystallography and, more recently, by transmission electron microscopy (TEM). A high-resolution crystal structure at $2.5 \AA$ (Fig. 2 ) reveals a compact architecture with a substantial amount of surface area $\left(3800 \AA^{2}\right)$ buried in intradomain interactions in contrast to other family members, such as c-kit and FGFR, which display an extended Ig domain arrangement (Barton et al. 2006). The compact structure $(\sim 90 \times 65 \times 50 \AA)$ is achieved as flexible linkers allow Ig1 to fold down and interact with the third Ig domain, creating an arrowhead arrangement. This leaves Ig2 as the tip of the arrowhead in position to interact with the angiopoietin ligands. Ig3, Ig1, and EGF3 form the base and two sides, respectively. EGF domains 1 and 2 are mostly buried, forming numerous contacts with the outer 4 domains to stabilize the overall structure. Four N-linked glycosylation sites are found in the crystal structure split between Ig1 and Ig3; however, their role in receptor function, if any, remains unknown (Barton et al. 2006). In agreement, MacDonald et al. (2006) analyzed the structure of the Tie2 ectodomain including the FNIII repeats by rotary shadow-cast TEM. They describe Tie2 as a "lollipop" structure with the compact Ig and EGF domains as the head and the FNIII repeats creating a stalk.

\section{Tie2-Angiopoietin Recognition}

In addition to the unique tertiary architecture of the Tie receptors, they are also distinct in their binding of the fibrinogen-like domain of the angiopoietin ligands. Typical Ig superfamily receptors have been shown to interact with members of the cysteine knot, four-helix bundle, and $\beta$-trefoil families; thus, the structures of Ang1 and Ang2 bound to the Tie2 receptor ectodomain revealed a novel ligand/receptor interaction (Wiesmann et al. 2000).

The first structure of Ang2-RBD bound to the Tie2 ectodomain (excluding the three FNIII repeats) confirmed that Ig2 of Tie 2 and the P domain of the ligand were exclusively responsible for ligand/receptor recognition and binding. The $3.5 \AA$ structure has overall dimensions of $130 \times 65 \times 50 \AA$ with one Ang2-RBD and one Tie 2 ectodomain in the complex, in congruence with the previously reported 1:1 binding stoichiometry (Fig. 2) (Barton et al. 2006). The small, uninterrupted binding interface (1300 ̊) is primarily dominated by van der Waals interactions between nonpolar side chains with additional stability resulting from a hydrogenbonding network and several salt bridges. The binding surface is adjacent to the conserved calcium-binding site of the Ang ligand P domain; however, the calcium ion does not appear to play a direct role in receptor recognition other than to stabilize the $\mathrm{P}$ domain. Independent biochemical studies show that disruption of $\mathrm{Ca}^{2+}$ binding does, in fact, result in disordered and receptor-binding incompetent ligand (Barton et al. 2005).

The structure of the ligand-receptor interface highlights yet another unique feature of the Ang-Tie system: it uses a lock-and-key mode of recognition similar to that of the antibody-antigen interactions. Both Tie2 and antibodies mediate recognition of their ligands through a molecular surface with complementary electrostatic and chemical properties. Each molecule of the heterodimer undergoes very little structural alteration on binding, primarily restricted to minor side chain rearrangements. Additional parallels between the Ang/Tie2 binding interface and antibody-antigen interactions include a relatively small amount of buried surface area (typically between 700-1150 ̊ for antigens), an abundance of aromatic residues, and van der Waals contacts, and/or hydrogen bonds mediating recognition (Barton et al. 2006; Sundberg 2009).

Biochemical studies have suggested that Ang1 and Ang2 interact with Tie2 using a common interface and that was confirmed by the crystal structure of the Ang1/Tie2 complex (Barton et al. 2006; Yu et al. 2013). The Ang1/Tie2 complex superimposes on the Ang2/Tie2 structure with few major alterations (rms deviation at $0.574 \AA$ for equivalent C $\alpha$ positions). Not surprisingly, the additional FNIII repeat, not present in earlier models, does not influence ligand binding and is located on the opposite face of the receptor. However, a small shift in the overall ligand position is observed $(\sim 1.5-6 \AA)$, despite 
Tie2 and Eph RTK Activation and Signaling

the involvement and preservation of most equivalent contact residues between Ang1 and Ang2 (Barton et al. 2006; Yu et al. 2013).

The unbound and Ang-bound Tie2 structures show few architectural changes. The only major deviation is within a surface loop of Ig2, which shifts slightly in the complex structure to facilitate ligand interactions; yet, the overall packing of the five domains remains essentially identical (Barton et al. 2006). Similarly, the angiopoietin structure undergoes minimal alteration on Tie2 binding. Two small variations include the $\mathrm{Ca}^{2+}$ ion-binding loop, which undergoes a small shift of approximately $1.0 \AA$ to create a van der Waals contact, and Ser480, which shifts $\sim 1.8 \AA$ to accommodate a hydrogen bond at the ligand-binding interface (Barton et al. 2005, 2006).

\section{Tie2 Tyrosine Kinase Domain Structure and Signaling}

The structures of both wild-type and a nonphosphorylatable mutant of the Tie2 tyrosine kinase catalytic domain (TKD) (residues 808-1124) were determined at 2.1-2.5 ̊̊ resolution (Shewchuk et al. 2000). The overall molecular architecture is comparable to previously determined protein kinases and contains a catalytic cleft between the smaller amino and larger carboxyl lobes (Fig. 3). The amino-terminal lobe (residues 808-904) contains two charged residues (K855, E872) and a glycine rich nucleotidebinding loop (residues 831-836) responsible for coordination of the $\alpha, \beta$, and $\gamma$ phosphates of ATP. The carboxy-terminal lobe (residues 905-1124) consists of seven $\alpha$-helices, four short $\beta$-strands, and an extended carboxy-terminal tail. The kinase active site consists of the catalytic loop (residues 962-968), including the essential aspartic residue (D964), and the activation loop (residues 982-1008) containing a single tyrosine residue (Y992).

Despite general similarity with many receptor tyrosine kinase domains, Tie2 TKD most closely resembles FGFR1 with $45 \%$ primary sequence identity, and an rmsd for the C $\alpha$ atoms of the carboxy-terminal and amino-terminal lobes of $0.76 \AA$ and $0.58 \AA$, respectively. Both kinase structures were determined in an "open" conformation, with relative rotations of $15^{\circ}$ between the $\mathrm{N}$ and $\mathrm{C}$ lobes compared with the "closed" conformation observed, for example, in IRK (Shewchuk et al. 2000).

Activation of many TKDs is thought to occur in trans via ligand-induced dimerization of the kinase domains. As opposed to the prototypic receptor tyrosine kinase, Tie2 signal initiation requires receptor tetramerization and/ or clustering facilitated by the multimeric an-
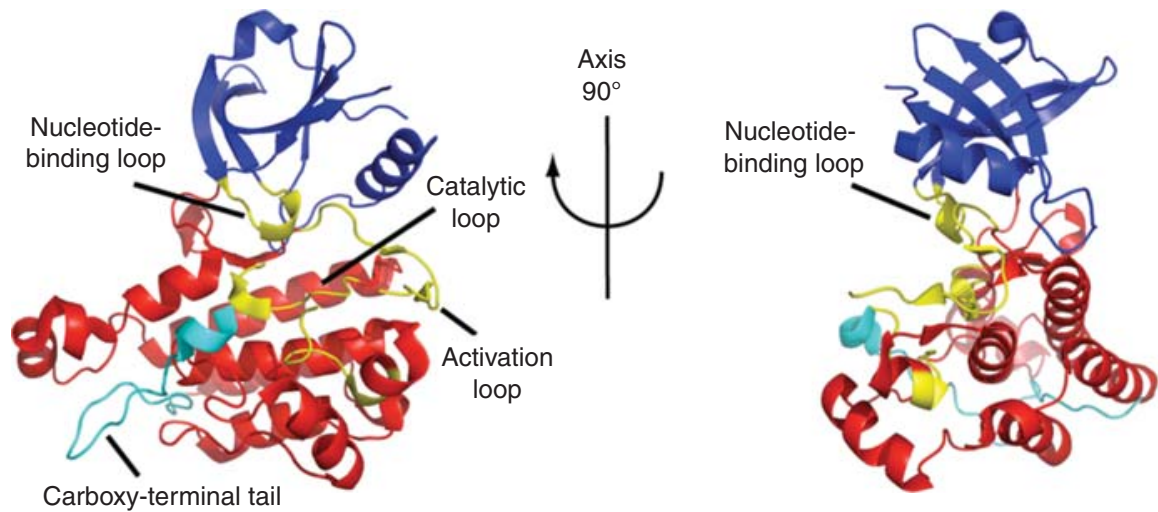

Figure 3. The structure of the Tie 2 TKD. Two views rotated $90^{\circ}$ about the $y$-axis are shown (PBD 1FVR). The two conserved lobes, amino terminal and carboxy terminal, are colored blue and red, respectively. The three catalytic loops are labeled and colored yellow. The extended carboxy-terminal tail, containing the substrate tyrosines 1101,1107 , and 1112, is colored cyan. 
W.A. Barton et al.

giopoietin ligands (Davis et al. 2003). Autophosphorylation and activation is inhibited primarily through an unproductive conformation of both the nucleotide-binding loop and charged residues responsible for ATP coordination. Interestingly, the activation loop in Tie2 adopts an overall "active conformation" independent of phosphorylation, somewhat analogous to ErbB receptors (Stamos et al. 2002). However, the carboxy-terminal tail adopts an extended conformation into the active site, presumably preventing substrate binding by acting as a substrate mimetic (Shewchuk et al. 2000). In support of this conclusion, a mutant kinase lacking 15 carboxy-terminal residues displays a drastic increase in kinase autophosphorylation, as compared with wild-type Tie2 (Niu et al. 2002).

Within the carboxy-terminal tail are three tyrosine residues, known to undergo reversible phosphorylation during signaling, that serve as important docking sites for various PTB and SH2 domain-containing proteins. Two of these residues, Y1101 and Y1112, are involved in extensive hydrogen bonding and van der Waals interactions with the core of the protein, a conformation that seemingly prevents their posttranslational modification. Therefore, a conformational change presumably occurs following activation that exposes Y1101, Y1107, and Y1112 for phosphorylation and subsequent binding events. Phospho-Y1101 has been shown to recruit Grb2 and the p85 subunit of PI3K, promoting cell motility and survival through the MAPK and Akt pathways, respectively (Huang et al. 1995; Kontos et al. 2002). Similarly, Phospho-Y1112 has been reported to recruit the protein tyrosine phosphatase, SH-PTP2, which in turn may negatively regulate Tie2 signaling (Huang et al. 1995). Additional studies aimed at inhibiting the activity of PI3K have shown Y1107 mediating cell mobility by recruitment of Dok-R in a PI3K independent mechanism (Master et al. 2001; Jones et al. 2003). Thus, like most other tyrosine kinase receptors, the Tie2 kinase domain is controlled through a combination of conformational changes involving the activation loop, nucleotide-binding loop, and carboxy-terminal domain.

\section{The Role of Tie1 in Tie2 Signaling}

The coreceptor Tiel is highly homologous to Tie2 yet does not associate with any of the angiopoietin ligands. Examination of the Tie2/ Ang2 interface in comparison with a Tie1 homology model illustrates that many of the residues essential for ligand recognition in Tie 2 are replaced in Tie1 with residues that would result in highly unfavorable contacts with an incoming ligand (Barton et al. 2006; Seegar et al. 2010). Instead of being directly activated by ligand binding, it appears that Tiel forms ligand-independent heterodimers with Tie 2 at the cell surface. Indeed, Tie1 contains a large basic surface, primarily composed of arginine and lysine residues, that forms a functional electrostatic interaction with a positively charged face of Tie2. Interestingly, the heterodimerization with Tiel mediates negative regulation of Tie2, inhibiting its phosphorylation and preventing downstream signaling (Fig. 4). This inhibition depends on the relative concentrations of Tie1 and Tie2 in an individual cell, a level of control that may vary between vascular and lymphatic endothelial cells. The different angiopoietin ligands are capable of eliciting various functional responses by either stabilizing or disrupting the Tie1/Tie2 complexes (Hansen et al. 2010; Seegar et al. 2010). A short (three residue) loop in the $P$ domain (see Fig. 2, left panel) adjacent to the Ang/Tie2 binding interface seems to mediate functional differences between the ligands ( $\mathrm{Yu}$ et al. 2013). This loop in the antagonist Ang2 permits Tie1/Tie2 heterodimerization, whereas the equivalent loop in the agonist Ang1 disrupts the electrostatic interaction, promoting Tie2 clustering and activation of downstream signaling cascades. The context-dependent activation of Tie2 by Ang2 likely occurs when Tie1 is not present in high concentrations within the cell, highlighting the complexity of Tie receptor regulation.

\section{Eph RECEPTORS AND EPHRINS}

Eph receptors, the largest family of receptor tyrosine kinases (RTKs) and their ephrin ligands (see also Lisabeth et al. 2013) have central roles in axon pathfinding and in a diverse array of 

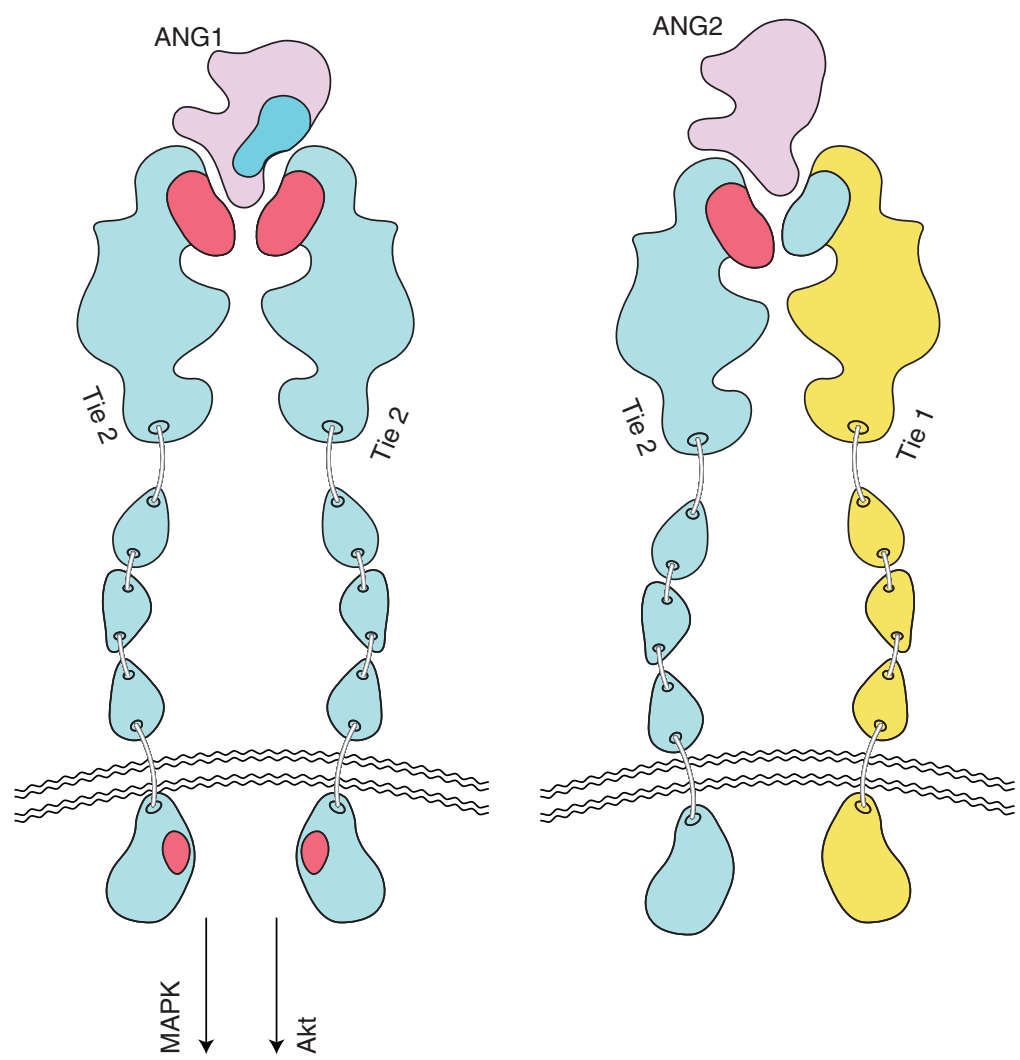

Figure 4. Model of Tie-angiopoietin signaling. The angiopoietin growth factors initiate complex signaling pathways through the Tie receptor tyrosine kinases on the endothelial cell surface. Ang1 activation of the primary receptor, Tie2, leads to prosurvival signaling through pathways such as Akt and MAPK, and results in endothelial cell quiescence and recruitment of surrounding support cells. Disruption of Tie2 signaling gives increase to a leaky vessel wall as support cells detach and endothelial cells begin to migrate. The interaction of Tie2 with its coreceptor Tiel leads to such a vessel branching phenotype. The context-dependent antagonist Ang2 inactivates the Tie2 receptor by facilitating the inhibitory Tie1/Tie2 interactions; however, if Tie1 is not present in the cell, Ang2 is capable of clustering and activating Tie2 in a manner similar to the agonist Ang1. Tie2 is in cyan, Tie1 is in yellow, and Ang1 and Ang2 are in magenta. Ang1 and Ang2 represent ligand dimers. Blue and red regions indicate electrostatically positive and negative surface regions, including phosphorylation of the Tie2 kinase domain.

other cell-cell interactions, including those of vascular endothelial cells and specialized epithelia (Flanagan and Vanderhaeghen 1998; Klein 2001; Himanen et al. 2007). The 16 Eph receptors and nine ephrins are divided into two subclasses based on sequence homology and binding affinities. The domain organization of Eph receptors and ephrins is shown in Figure 5. As both receptors and ligands are membranebound, their interactions at sites of cell-cell contact initiate unique bidirectional signaling cascades (Cowan and Henkemeyer 2001). The signaling downstream of the Ephs is referred to as "forward" and downstream of the ephrins as "reverse." Whereas the receptor-induced activation of the B-class ephrins is well documented (Cowan and Henkemeyer 2002; Song et al. 2002; Klein 2009; Lee and Daar 2009), the A-class ligands lack a cytoplasmic domain and their downstream signaling mechanism is less clear. It has been suggested that $\operatorname{TrkB}$ is a coreceptor for ephrin-A5 and is necessary for A-class reverse signaling (Marler et al. 2008) but the details are still unknown. 
W.A. Barton et al.

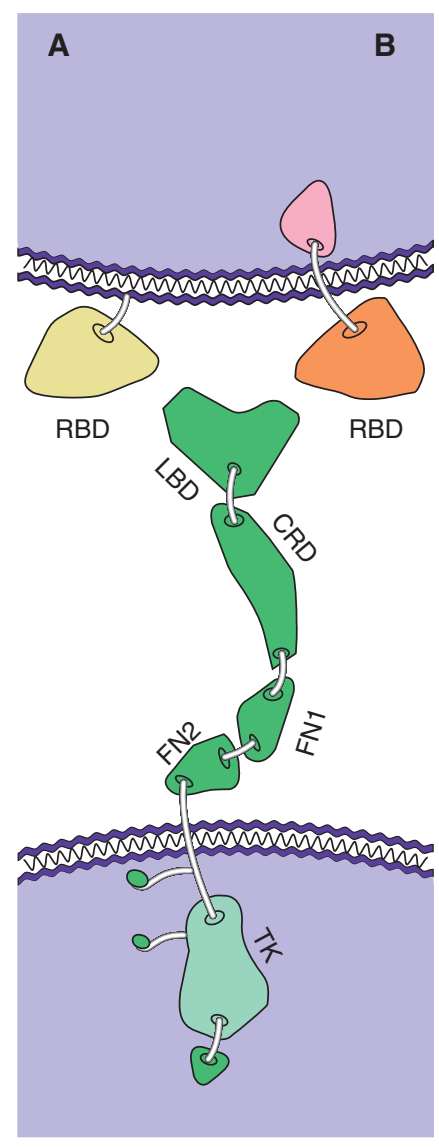

Figure 5. Schematic representation of A and B types of ephrins and Eph receptors. Shown are the receptor-binding domain (RBD) of the ephrins, the Eph's ligand-binding domain (LBD), the kinase domain (TK), the Cys-rich domain (CRD), and the fibronectin III domains (FN3). The A ephrin family are GPIlinked to the membrane, whereas the B ephrin family has a transmembrane domain and a short cytoplasmic tail.

Although Ephs and ephrins were originally identified as axon guidance molecules, they have been implicated in a vast array of cell communication events. Those include bone morphogenesis and homeostasis, immunological and inflammatory host responses, stem cell plasticity, learning and memory, and Alzheimer's disease (Pasquale 2008). However, currently, the most intensely studied function of the Eph/ephrin system is that during development and progression of cancer in multiple cell types. Many A and
$B$ class receptors were shown to be overexpressed in various tumor types (Robinson et al. 1996; Hafner et al. 2004; Noblitt et al. 2005; Sjoblom et al.2006) and to regulate critical steps of blood vessel formation (vasculogenesis) and remodeling (angiogenesis) and hence tumor growth. Eph receptors are also implicated in tumor invasion and metastasis (Wang 2011). Intriguingly, they have a dual role in tumorous cells, sometimes promoting sometimes suppressing cancer growth (Chen et al. 2008). Given their importance in multiple aspects of cancer progression, it is not surprising that there is widespread interest in developing Eph-targeted anticancer therapeutics (Pasquale 2010).

\section{Eph/Ephrin Recognition and Binding}

The structural details of how the Eph receptors and ephrins bind each other have been well studied and documented and have been recently reviewed (Himanen 2012). Consequently, we will give here only a brief overview on the fundamentals of ligand-receptor recognition. Overall, it has been known for more than two decades that the amino-terminal globular domains of Eph receptors and ephrins are necessary and sufficient for binding (Labrador et al. 1997). Later structural studies revealed how the ephrin minimal interaction domain forms an initial high-affinity $1: 1$ complex with the Eph receptor minimal interaction domain by inserting its long G-H loop into a hydrophobic cavity on the surface of the receptor (Himanen et al. 2001; Himanen and Nikolov 2002). The same mode for initiation of receptor-ligand interactions on cell-cell contact is the same for all investigated cases, regardless of whether the interaction is between A-class or Bclass molecules, or whether it is cross-class ( $\mathrm{Hi}-$ manen 2012). Individual differences do exist between different complexes, mainly in the intimacy of the contacts surrounding the central G-Hloop/cavity interface and in the conformational changes of the interacting loops, and these differences are responsible for fine-tuning the interactions.

Based on seemingly class-specific differences in the flexibility of the receptor loops forming the sides of the binding cavity, B-class Eph/eph- 
rin binding has been referred to as "induced fit," whereas the A-class binding has been referred to as "lock-and-key" (Himanen et al. 2009). Studies on EphA4, a receptor that is able to bind both classes of ligands, have been particularly informative in terms of explaining the mechanism of initial receptor-ligand recognition and subclass specificity (Bowden et al. 2009; Qin et al. 2010). EphA4 displays significant structural plasticity, especially in the ligand-binding loops and one study reported 16 different conformations, obtained from two EphA4 crystal forms (Qin et al. 2012), highlighting the key role of Eph protein dynamics on recognition and signaling. Although it is now known that other regions, outside the minimal binding domains of the molecules, also participate in the formation of Eph/ ephrin complexes (Day et al. 2005; Himanen et al. 2010; Seiradake et al. 2010), there is no evidence that they increase the association rate measured for the minimal binding domains. It is evident, however, that they are essential for the formation of the stable receptor clusters necessary for the full biological activity of these molecules.

\section{Eph/Ephrin Interaction Interfaces as Drug Targets}

All known Eph/ephrin structures highlight the importance of the hydrophobic cavity/loop for Eph/ephrin binding. This has prompted an intense investigation toward identifying Eph agonists/antagonists targeting this region that could be developed into therapeutic agents. Several structures were determined to show how the hydrophobic cavity of the receptor, indeed, provides a binding pocket for peptides and small organic molecules (Chrencik et al. 2006, 2007; Qin et al. 2008; Noberini et al. 2012b). For example, an EphB4-specific peptide binds to this channel and blocks EphB4 signaling (Chrencik et al. 2006), whereas other peptides bind selectively to EphA2 with submicromolar Kd and compete with ephrin binding (Koolpe et al. 2002). Remarkably, one of these peptides has ephrin-like activity (i.e., it stimulates EphA2 tyrosine phosphorylation and signaling). It was further revealed that only five peptide residues might be essential for receptor binding and selectivity (Mitra et al. 2010). Antagonistic peptides that target the ligand-binding pocket of EphA4 were also identified (Lamberto et al. 2012). Recently, lower-resolution NMR structures of two small organic molecules binding in the same hydrophobic cavity of EphA2 and EphA4 were published (Noberini et al. 2008; Qin et al.2008). The compounds act as competitive inhibitors for ephrin-A5, selectively binding to EphA2 and EphA4. They inhibit ephrininduced phosphorylation without affecting cell viability or phosphorylation of other receptor tyrosine kinases and, importantly, also inhibit EphA2-dependent retraction of the cell periphery in prostate cancer cells. Moreover, natural compounds such as lithocholic acid (Giorgio et al. 2011) and tea polyphenols (Noberini et al. 2012a), have also been shown to inhibit ephrin binding to EphA4 and several other Eph receptors at low micromolar concentrations. Some of the polyphenols were shown to inhibit tyrosine phosphorylation, which was affected by mutations within the ligand-binding cavity of EphA4. This year, the first small-molecule agonist (doxazosin) for any RTKwas identified (Petty et al. 2012). It not only inhibits EphA2-dependent Akt and ERK activation but, remarkably, also reduces metastasis of human prostate cancer cells in a mouse xenograft model.

These studies suggest that small-molecule inhibitors, selected based on their ability to disrupt ephrin-Eph interactions, can display a wide range of biological effects and have clear pharmaceutical potential. What remains to be seen is whether it is possible to also target the other Eph receptor interfaces, those outside of the ephrin-binding domain, which are lower affinity and presumably even easier to disrupt. With the publication of the three-dimensional structures of the complete Eph ectodomains (Himanen et al. 2010 ; Seiradake et al. 2010) (see also below), we expect to see rapid progress in this direction. Finally, it is also possible to target the ephrin ligand, as has been performed by using an ephrin-specific antibody (Abengozar et al. 2012), the systemic administration of which caused a reduction of tumor growth in xenografted mice. 
W.A. Barton et al.

\section{Eph Receptor Clustering and Activation}

The structural studies on the minimal binding domains have fairly rapidly given us a comprehensive understanding of the initial Eph/ephrin recognition steps. However, until recently, there were no studies describing the structural rearrangements taking place within the full receptor molecules on ligand binding. This knowledge is essential for understanding the events that trigger the formation of receptor clusters necessary for downstream signaling. During the past couple of years, however, a string of papers have provided considerably better view on these events. They include structural studies of the entire Eph ectodomains, biophysical studies on their transmembrane domains, as well as structural, biophysical, and cell biological studies on their intracytoplasmic regions.

Two papers on the structures of the extracellular domain (ECD) of the Eph receptor (Himanen et al. 2010; Seiradake et al. 2010) have now shed light on ligand-induced Eph clustering. The papers describe structures for the complete or partial EphA2 ECD, either alone or in complex with ephrin-A1 or -A5 ligands. The structures reveal that the Eph-ECD folds into a rigid, rod-like structure that does not significantly change on ligand binding. Thus, ligand-induced conformational changes in the receptor ectodomain do not seem to be the underlying molecular mechanism of Eph signal transduction. The structures further show how Eph receptors use two different interacting surface areas to generate signaling clusters (Fig. 6). The first interface is within the ligand-binding domain of Eph and causes the formation of receptor dimers. The second interacting surface is a novel protein-interaction module within the Cys-rich domain (CRD) that cooperates with ligand-mediated clustering to cause the formation of continuous signaling Eph/Eph assemblies. Thus, once the receptor concentration is high enough, a receptor dimer can associate with two other receptor dimers through the second interacting interfaces. The ensuing receptor hexamer can then again bind other receptor dimers and so on, using a so-called "seeding" mechanism, resulting in the formation of large receptor assemblies (clusters)

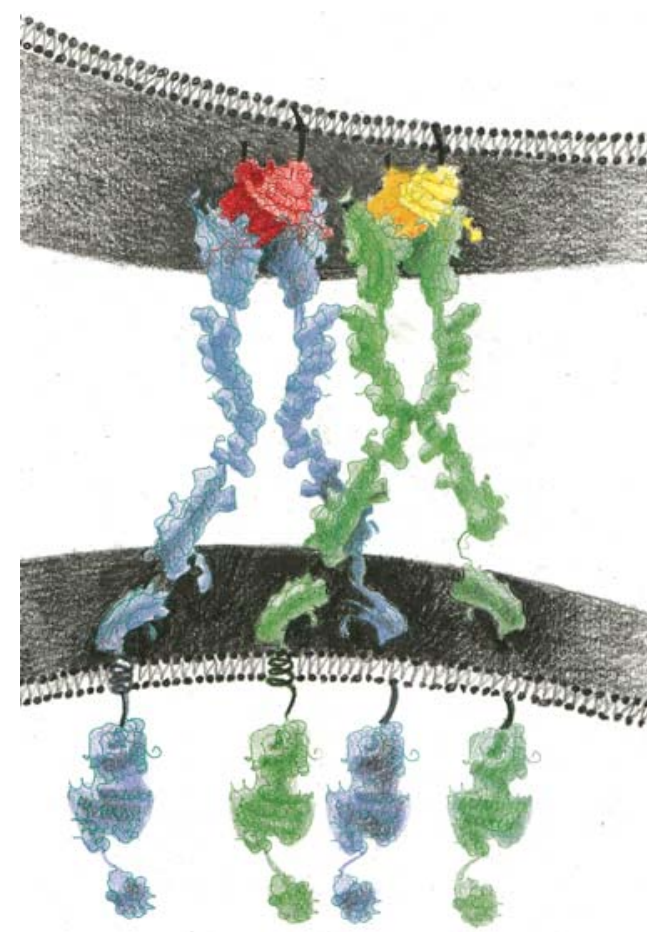

Figure 6. Schematic presentation of the Eph receptors bound to ephrin ligands at the cell-cell contact regions. Eph receptors are in blue and green, the ephrins are in red and yellow. The receptors use a "seeding" mechanism for creating signaling-competent assemblies where the ligand-binding domains first form receptor dimers (2:2 Eph/ephrin complexes), after which they bind other dimers via their cystein-rich domains, thus creating large clusters containing hundreds of molecules. Seemingly, the main role of the ligand is to increase the local receptor concentration so that full downstream signaling can be attained.

that have been visualized on the cell surface. At high receptor concentrations, this process can also happen independently of ligand binding (Wimmer-Kleikamp et al. 2004), potentially leading to transforming phenotypes. Indeed, nearly half of human breast cancers overexpress the EphA2 receptor (Lackmann and Boyd 2008). The presence of highly ordered receptor assemblies on the cell surface is a unique feature of the Eph receptors within the receptor kinase superfamily. The function of ephrin ligands seems to be to increase local receptor concentration so that these Eph/Eph and Eph/ephrin assemblies 
can be formed. Moreover, EphA and EphB receptors can cocluster so that the assembly of one receptor type promotes the recruitment and activation of the other receptor (Janes et al. 2011). Studies of receptor clustering also include treating cells with antibodies that recognize the Eph ectodomain, consequently inducing Eph receptor activation and initiation of downstream signaling (Vearing et al. 2005).

\section{Transmembrane Domains in Eph Activation}

In addition to the ECD, the transmembrane domains (TMDs) of receptor tyrosine kinases play an active role in signaling, contributing to the stability of receptor dimers or maintaining a signaling-competent receptor conformation. Earlier interpretations of the role of TMD were based on biophysical studies using various RTKs (Li and Hristova 2006; Artemenko et al. 2008; Bocharov et al. 2008, 2010; Li and Hristova 2010; Volynsky et al. 2010). Some understanding of the participation of TMD in the biological activity of RTKs came from studies that showed how isolated TMDs of EGFR and other members of the ErbB family dimerize in bacterial membrane (Mendrola et al. 2002). A recent NMR study shows that the membrane-spanning helices of ErbB4 form a parallel dimer in lipid bicelles and undergo a structural adjustment to form a network of intermonomeric polar contacts and provide entropic enhancement for the weak helix-helix interactions (Bocharov et al. 2012). Interestingly, when thousands of peptides, based on the TMD of ErbB2 (Neu) were screened for their dimerization properties, some of the sequences were found to activate the ErbB2 kinase significantly more than the wildtype sequence (He et al. 2011), further highlighting the potential importance of this region. In addition, the isolated FGFR TMD was shown to dimerize in the absence of the extracellular domain or ligands ( $\mathrm{Li}$ et al. 2005). However, this dimerization propensity is about tenfold weaker than that of glycophorinA (Artemenko et al. 2008), a well-characterized TMD dimer. Recent structures of the EphA1 and EphA2 TMDs also suggest that they mediate lateral movement and functional dimerization of the receptors (Bocharov et al. 2008, 2010; Volynsky et al. 2010). Interestingly the NMR structure of the dimeric transmembrane domain of EphA2 embedded into lipid bicelle shows a left-handed parallel packing of the transmembrane helices (Bocharov et al. 2010), whereas the same TMD motif of EphA1 favors right-handed helical packing (Bocharov et al. 2008).

How the Eph preceptor TMD mediates, if at all, the phosphorylation of the kinase domain has remained elusive. Studies on other RTKs have suggested two different models. According to the first one, not only the conformation of the ECD is different ("closed") in the absence of ligand, but also the TMDs do not interact productively through their dimerization motifs (Moriki et al. 2001; Schlessinger 2003). Ligand binding causes a rotation of the TMDs, positioning the catalytic domains in a signaling-competent orientation ("open"). For example, in the case of the insulin receptor that is constitutively dimeric, ligand binding would bring the TMDs closer together, allowing a more intimate contact of the catalytic subunits (Ottensmeyer et al. 2000). The other mechanism proposes that the receptor is in the "open" conformation even before ligand binding, but the TMD-mediated receptor dimers are not stable. The dimers would then be stabilized on ligand binding without undergoing major conformational changes (Cho et al. 2003; Li and Hristova 2006). The biological and biophysical studies discussed above suggest that the Eph receptors use the latter mechanism. Furthermore, their ligand-independent autophosphorylation in several cancers and the colocalization of mixed subclasses of Eph receptors in the same lipid rafts (Janes et al. 2011) point to the existence of signaling-competent assemblies even in the absence of ligand stimulation. On the other hand, full downstream signaling that follows full phosphorylation of the receptors requires ligand-induced formation of large-sized clusters (Janes et al. 2012).

\section{Eph Kinase Domain Activation}

Although the exact role of the ECD and TMD multimerization and clustering in signaling initiation is still not fully understood, the structural 
W.A. Barton et al.

changes that the activation causes in the kinase domain (TKD) are well-studied and reviewed (Wybenga-Groot et al. 2001; Nowakowski et al. 2002; Hubbard 2004; Hubbard and Miller 2007; Lemmon and Schlessinger 2010). The general mechanisms and principals of TKD activation are also used by the Eph receptors. Catalytic activation involves auto-phosphorylation of two key tyrosines in the juxtamembrane segment (JMS) and one tyrosine in the activation loop at the active center of the kinase. In the unphosphorylated, autoinhibitory state, an $\alpha$-helix in the EphB2 JMS suppresses the catalytic activity by an intimate association with the amino-terminal lobe of the kinase domain. Phosphorylation of the JMS tyrosines induces disorder in the JMS and dissociation from the kinase. This dissociation occurs without major structural changes but with partial ordering of the activation segment. An important Eph characteristic is that kinase phosphorylation also causes increased flexibility between the amino- and the carboxy-terminal TKD lobes (Wiesner et al. 2006), which is correlated with the kinase activity. Later studies on EphA3 have shown that the JMS also affects the activation segment through a separate pathway that includes a tyrosine residue in the active center and a serine in the amino terminus of the activation segment (Davis et al. 2008). These detailed structural studies have prompted efforts to discover structure-based second-generation kinase inhibitors (Choi et al. 2009).

Interestingly, the Eph receptors display some unique TKD phosphorylation and activation features. A recent study used semisynthetic (Singla et al. 2008) Eph receptors to document a sequential and ordered autophosphorylation process in which the carboxy-terminal JMS tyrosine is always phosphorylated first, followed by the amino-terminal JMS tyrosine, and, finally, by the activation loop tyrosine (Singla et al. 2011). This is in contrast with observations for most other receptor kinases in which the kinase activation loop is phosphorylated first (e.g., Furdui et al. 2006). The observed phosphorylation time-dependences coupled with site-directed mutagenesis further revealed that the Eph kinase activity directly correlates with the phosphory- lation status of the juxtamembrane region, and in particular with the carboxy-terminal JMS tyrosine, and not that of the activation loop tyrosine. This is in contrast to the accepted view for most other characterized protein kinases.

Just as the phosphorylation of the tyrosine residues is important for activation of kinase receptors, dephosphorylation by phosphatases is crucial for their negative control. Protein tyrosine phosphatase (PTP) receptor type $\mathrm{O}$ (Ptpro) has been shown to specifically dephosphorylate both A- and B-type Eph receptors (Shintani et al. 2006). Ptpro dephosphorylates the same carboxy-terminal JMS tyrosine residue that is required for receptor activation and, hence, seems to regulate the threshold of the response of Eph receptors to ephrins. Another study suggests that PTP activity switches the response to ephrin from repulsion to adhesion and, thus, may play a role in the pathology of tumors (Wimmer-Kleikamp et al. 2008). Furthermore, it has been shown that there is a direct interaction between a PTP and EphA3 before ligand-stimulation (Nievergall et al. 2010). These studies are paving the way for understanding the precise roles of PTPs in regulating Eph signaling.

\section{Termination of Eph Signaling}

The balance between Eph kinase activation and signaling termination is relatively poorly understood. Because the main mechanism for Eph signaling termination is receptor internalization and degradation following ephrin binding and because the Eph/ephrin complexes are extremely stable once formed, mechanisms should exist that allow the endocytosis of Eph/ephrin complexes. Moreover because the signaling is most often repulsive, these mechanisms should allow for quick separation of the interacting cells without damaging the cell membranes at the contact regions. There are currently two models to explain how this occurs-ectodomain cleavage and "transendocytosis." According to the first, on Eph/ephrin complex formation, the Ephs, the ephrins, or both are cleaved from the membrane surface by proteases. Indeed it has been well documented that the GPI-anchored eph- 
Tie2 and Eph RTK Activation and Signaling

rin-A ligands are cleaved off the cell membrane by ADAM10 (A disintegrin and metalloprotease). Originally, ADAM10 was shown to associate with ephrin-A2 in cis, with both proteins on the surface of the same cell, while EphA3 on the opposing cell was also required for efficient ephrin cleavage (Hattori et al. 2000). A later study, however, showed that ADAM10 is constitutively associated with EphA3 and ligand-binding repositions ADAM10 to activate the cleavage of ephrin-A5 in trans from the membrane of the opposing cell (Janes et al. 2005). The consequence in both cases is ephrin shedding on receptor binding allowing the opposing cells to detach and the Eph/ephrin complexes to be internalized in the Eph-expressing cell. It has also been suggested that activation of Eph receptors cause extension of their intracellular domains away from the cell membrane facilitating a direct physical association with ADAM10 and consequent ligand shedding (Janes et al. 2009).

The second model, transendocytosis, suggests that Eph/ephrin complexes are removed in both interacting cells via endocytic vesicles that are formed rapidly on cell-cell contact (Marston et al. 2003; Zimmer et al. 2003; Lauterbach and Klein 2006). Just as in ADAM-mediated cleavage, the intracellular domains of the proteins regulate these events, with carboxy-terminal Eph truncations being able to change forward to reverse or bidirectional endocytosis. Interestingly, the "transendocytosis" is currently the only internalization/degradation mechanism documented for B-type complexes.

\section{Conclusion and Perspectives}

Studies of the Tie-angiopoietin and Eph/ephrin signaling systems during the past two decades have provided significant insight into the activation and function of these vital signaling pathways in the healthy organism and in disease. Structural studies have visualized the initial ligand-receptor interaction events and have provided a foundation for the development of compounds targeting these interactions for the potential treatment of conditions as diverse as cancer, cardiovascular disease, neurological disorders, and spinal cord injury. What is not yet fully understood is how the initial ligand-receptor interactions are translated into kinase domain activation and initiation of downstream signaling. Toward that, novel approaches are being used for the production of full-length receptors for biochemical and structural studies in solution and in liposomes. In addition, highresolution visualization techniques are being developed to monitor the ligand-receptor interactions and clustering at the surface of live cells, as well as the interactions of the receptors with coreceptors, regulatory molecules such as phosphatases and proteinases, and downstream effectors such as scaffold proteins. Because both Eph receptors and Tie2 require the formation of higher-order clusters as signaling centers, the interplay between kinase and phosphatase activity at these sites is particularly important for the regulation of signaling. Another area of ongoing interest is the regulation of receptor internalization and degradation and/or recycling, including potential receptor signaling from within the endocytic vesicles.

\section{ACKNOWLEDGMENTS}

We thank all members of our laboratories for their work on Eph receptors and Ties. This research was supported by grants from the National Institutes of Health 1RO1CA127501 to W.A.B. and 1RO1HL077249 and RO1NS038486 to D.B.N., as well as pilot project funding from the Massey Cancer Center and School of Medicine (VCU) to W.A.B.

\section{REFERENCES}

${ }^{*}$ Reference is also in this collection.

Abengozar MA, de Frutos S, Ferreiro S, Soriano J, Perez-Martinez M, Olmeda D, Marenchino M, Canamero M, Ortega S, Megias D, et al. 2012. Blocking ephrinB2 with highly specific antibodies inhibits angiogenesis, lymphangiogenesis, and tumor growth. Blood 119: 4565-4576.

Adams RH, Alitalo K. 2007. Molecular regulation of angiogenesis and lymphangiogenesis. Nat Rev 8: 464-478.

Artemenko EO, Egorova NS, Arseniev AS, Feofanov AV. 2008. Transmembrane domain of EphA1 receptor forms dimers in membrane-like environment. Biochim Biophys Acta 1778: 2361-2367.

Barton WA, Tzvetkova D, Nikolov DB. 2005. Structure of the angiopoietin-2 receptor binding domain and identifica- 
W.A. Barton et al.

tion of surfaces involved in Tie2 recognition. Structure 13: $825-832$.

Barton WA, Tzvetkova-Robev D, Miranda EP, Kolev MV, Rajashankar KR, Himanen JP, Nikolov DB. 2006. Crystal structures of the Tie2 receptor ectodomain and the angiopoietin-2-Tie2 complex. Nat Struct Mol Biol 13: 524532.

Bocharov EV, Mayzel ML, Volynsky PE, Goncharuk MV, Ermolyuk YS, Schulga AA, Artemenko EO, Efremov RG, Arseniev AS. 2008. Spatial structure and pH-dependent conformational diversity of dimeric transmembrane domain of the receptor tyrosine kinase EphA1. J Biol Chem 283: 29385-29395.

Bocharov EV, Mayzel ML, Volynsky PE, Mineev KS, Tkach EN, Ermolyuk YS, Schulga AA, Efremov RG, Arseniev AS. 2010. Left-handed dimer of EphA2 transmembrane domain: Helix packing diversity among receptor tyrosine kinases. Biophys J 98: 881-889.

Bocharov EV, Mineev KS, Goncharuk MV, Arseniev AS. 2012. Structural and thermodynamic insight into the process of "weak" dimerization of the ErbB4 transmembrane domain by solution NMR. Biochim Biophys Acta 1818: $2158-2170$.

Bowden TA, Aricescu AR, Nettleship JE, Siebold C, Rahman-Huq N, Owens RJ, Stuart DI, Jones EY. 2009. Structural plasticity of eph receptor A4 facilitates cross-class ephrin signaling. Structure 17: 1386-1397.

Chen J, Zhuang G, Frieden L, Debinski W. 2008. Eph receptors and Ephrins in cancer: Common themes and controversies. Cancer Res 68: 10031-10033.

Cho HS, Mason K, Ramyar KX, Stanley AM, Gabelli SB, Denney DW Jr, Leahy DJ. 2003. Structure of the extracellular region of HER2 alone and in complex with the Herceptin Fab. Nature 421: 756-760.

Choi Y, Syeda F, Walker JR, Finerty PJ Jr, Cuerrier D, Wojciechowski A, Liu Q, Dhe-Paganon S, Gray NS. 2009. Discovery and structural analysis of Eph receptor tyrosine kinase inhibitors. Bioorg Med Chem Lett 19: 4467-4470.

Chrencik JE, Brooun A, Recht MI, Kraus ML, Koolpe M, Kolatkar AR, Bruce RH, Martiny-Baron G, Widmer H, Pasquale EB, et al. 2006. Structure and thermodynamic characterization of the EphB4/Ephrin-B2 antagonist peptide complex reveals the determinants for receptor specificity. Structure 14: 321-330.

Chrencik JE, Brooun A, Recht MI, Nicola G, Davis LK, Abagyan R, Widmer H, Pasquale EB, Kuhn P. 2007. Three-dimensional structure of the EphB2 receptor in complex with an antagonistic peptide reveals a novel mode of inhibition. J Biol Chem 282: 36505-36513.

Cowan CA, Henkemeyer M. 2001. The SH2/SH3 adaptor Grb4 transduces B-ephrin reverse signals. Nature 413: $174-179$.

Cowan CA, Henkemeyer M. 2002. Ephrins in reverse, park and drive. Trends Cell Biol 12: 339-346.

Davis S, Aldrich TH, Jones PF, Acheson A, Compton DL, Jain V, Ryan TE, Bruno J, Radziejewski C, Maisonpierre PC, et al. 1996. Isolation of angiopoietin-1, a ligand for the TIE2 receptor, by secretion-trap expression cloning. Cell 87: 1161-1169.

Davis S, Papadopoulos N, Aldrich TH, Maisonpierre PC, Huang T, Kovac L, Xu A, Leidich R, Radziejewska E, Rafique A, et al. 2003. Angiopoietins have distinct mod- ular domains essential for receptor binding, dimerization and superclustering. Nat Struct Biol 10: 38-44.

Davis TL, Walker JR, Loppnau P, Butler-Cole C, Allali-Hassani A, Dhe-Paganon S. 2008. Autoregulation by the juxtamembrane region of the human ephrin receptor tyrosine kinase A3 (EphA3). Structure 16: 873-884.

Day B, To C, Himanen JP, Smith FM, Nikolov DB, Boyd AW, Lackmann M. 2005. Three distinct molecular surfaces in ephrin-A5 are essential for a functional interaction with EphA3. J Biol Chem 280: 26526-26532.

Fiedler U, Krissl T, Koidl S, Weiss C, Koblizek T, Deutsch U, Martiny-Baron G, Marme D, Augustin HG. 2003. Angiopoietin- 1 and angiopoietin- 2 share the same binding domains in the Tie-2 receptor involving the first Ig-like loop and the epidermal growth factor-like repeats. J Biol Chem 278: $1721-1727$.

Flanagan JG, Vanderhaeghen P. 1998. The ephrins and Eph receptors in neural development. Annu Rev Neurosci 21: 309-345.

Furdui CM, Lew ED, Schlessinger J, Anderson KS. 2006. Autophosphorylation of FGFR1 kinase is mediated by a sequential and precisely ordered reaction. Mol Cell 21: 711-717.

Giorgio C, Hassan Mohamed I, Flammini L, Barocelli E, Incerti M, Lodola A, Tognolini M. 2011. Lithocholic acid is an Eph-ephrin ligand interfering with Eph-kinase activation. PloS ONE 6: e18128.

Hafner C, Schmitz G, Meyer S, Bataille F, Hau P, Langmann T, Dietmaier W, Landthaler M, Vogt T. 2004. Differential gene expression of Eph receptors and ephrins in benign human tissues and cancers. Clin Chem 50: 490-499.

Hansen TM, Singh H, Tahir TA, Brindle NP. 2010. Effects of angiopoietins- 1 and -2 on the receptor tyrosine kinase Tie2 are differentially regulated at the endothelial cell surface. Cell Signal 22: 527-532.

Hattori M, Osterfield M, Flanagan JG. 2000. Regulated cleavage of a contact-mediated axon repellent. Science 289: $1360-1365$.

He L, Hoffmann AR, Serrano C, Hristova K, Wimley WC. 2011. High-throughput selection of transmembrane sequences that enhance receptor tyrosine kinase activation. J Mol Biol 412: 43-54.

Himanen JP. 2012. Ectodomain structures of Eph receptors. Semin Cell Dev Biol 23: 35-42.

Himanen JP, Nikolov DB. 2002. Purification, crystallization and preliminary characterization of an Eph-B2/ ephrin-B2 complex. Acta Crystallogr D Biol Crystallogr 58: $533-535$.

Himanen JP, Rajashankar KR, Lackmann M, Cowan CA, Henkemeyer M, Nikolov DB. 2001. Crystal structure of an Eph receptor-ephrin complex. Nature 414: 933-938.

Himanen JP, Saha N, Nikolov DB. 2007. Cell-cell signaling via Eph receptors and ephrins. Curr Opin Cell Biol 19: 534-542.

Himanen JP, Goldgur Y, Miao H, Myshkin E, Guo H, Buck M, Nguyen M, Rajashankar KR, Wang B, Nikolov DB. 2009. Ligand recognition by A-class Eph receptors: Crystal structures of the EphA2 ligand-binding domain and the EphA2/ephrin-A1 complex. EMBO Rep 10: 722-728.

Himanen JP, Yermekbayeva L, Janes PW, Walker JR, Xu K, Atapattu L, Rajashankar KR, Mensinga A, Lackmann M, 
Nikolov DB, et al. 2010. Architecture of Eph receptor clusters. Proc Natl Acad Sci 107: 10860-10865.

Huang L, Turck CW, Rao P, Peters KG. 1995. GRB2 and SHPTP2: Potentially important endothelial signaling molecules downstream of the TEK/TIE2 receptor tyrosine kinase. Oncogene 11: 2097-2103.

Huang H, Bhat A, Woodnutt G, Lappe R. 2010. Targeting the ANGPT-TIE2 pathway in malignancy. Nat Rev Cancer 10: 575-585.

Hubbard SR. 2004. Juxtamembrane autoinhibition in receptor tyrosine kinases. Nat Rev Mol Cell Biol 5: 464-471.

Hubbard SR, Miller WT. 2007. Receptor tyrosine kinases: mechanisms of activation and signaling. Curr Opin Cell Biol 19: 117-123.

Janes PW, Saha N, Barton WA, Kolev MV, Wimmer-Kleikamp SH, Nievergall E, Blobel CP, Himanen JP, Lackmann M, Nikolov DB. 2005. Adam meets Eph: An ADAM substrate recognition module acts as a molecular switch for ephrin cleavage in trans. Cell 123: 291-304.

Janes PW, Wimmer-Kleikamp SH, Frangakis AS, Treble K, Griesshaber B, Sabet O, Grabenbauer M, Ting AY, Saftig P, Bastiaens PI, et al. 2009. Cytoplasmic relaxation of active Eph controls ephrin shedding by ADAM10. PLoS Biol 7: e1000215.

Janes PW, Griesshaber B, Atapattu L, Nievergall E, Hii LL, Mensinga A, Chheang C, Day BW, Boyd AW, Bastiaens PI et al. 2011. Eph receptor function is modulated by heterooligomerization of A and B type Eph receptors. J Cell Biol 195: 1033-1045.

Janes PW, Nievergall E, Lackmann M. 2012. Concepts and consequences of Eph receptor clustering. Semin Cell Dev Biol 23: 43-50.

Jones N, Chen SH, Sturk C, Master Z, Tran J, Kerbel RS, Dumont DJ. 2003. A unique autophosphorylation site on Tie2/Tek mediates Dok-R phosphotyrosine binding domain binding and function. Mol Cell Biol 23: 2658-2668.

Klein R. 2001. Excitatory Eph receptors and adhesive ephrin ligands. Curr Opin Cell Biol 13: 196-203.

Klein R. 2009. Bidirectional modulation of synaptic functions by Eph/ephrin signaling. Nat Neurosci 12: 15-20.

Kontos CD, Cha EH, York JD, Peters KG. 2002. The endothelial receptor tyrosine kinase Tiel activates phosphatidylinositol 3-kinase and Akt to inhibit apoptosis. Mol Cell Biol 22: 1704-1713.

Koolpe M, Dail M, Pasquale EB. 2002. An ephrin mimetic peptide that selectively targets the EphA2 receptor. J Biol Chem 277: 46974-46979.

Labrador JP, Brambilla R, Klein R. 1997. The N-terminal globular domain of Eph receptors is sufficient for ligand binding and receptor signaling. EMBO J 16: 3889-3897.

Lackmann M, Boyd AW. 2008. Eph, a protein family coming of age: more confusion, insight, or complexity? Sci Signal 1: pre2.

Lamberto I, Qin H, Noberini R, Premkumar L, Bourgin C, Riedl SJ, Song J, Pasquale EB. 2012. Distinctive binding of three antagonistic peptides to the ephrin-binding pocket of the EphA4 receptor. Biochem J 445: 47-56.

Lauterbach J, Klein R. 2006. Release of full-length EphB2 receptors from hippocampal neurons to cocultured glial cells. J Neurosci 26: 11575-11581.
Lee HS, Daar IO. 2009. EphrinB reverse signaling in cell-cell adhesion: Is it just par for the course? Cell Adh Migr 3: 250-255.

Lemmon MA, Schlessinger J. 2010. Cell signaling by receptor tyrosine kinases. Cell 141: 1117-1134.

Li E, Hristova K. 2006. Role of receptor tyrosine kinase transmembrane domains in cell signaling and human pathologies. Biochemistry 45: 6241-6251.

Li E, Hristova K. 2010. Receptor tyrosine kinase transmembrane domains: Function, dimer structure and dimerization energetics. Cell Adh Migr 4: 249-254.

Li E, You M, Hristova K. 2005. Sodium dodecyl sulfatepolyacrylamide gel electrophoresis and forster resonance energy transfer suggest weak interactions between fibroblast growth factor receptor 3 (FGFR3) transmembrane domains in the absence of extracellular domains and ligands. Biochemistry 44: 352-360.

* Lisabeth EM, Falivelli G, Pasquale EB. 2013. Eph receptor signaling and ephrins. Cold Spring Harb Perspect Biol 5: a009159.

Macdonald PR, Progias P, Ciani B, Patel S, Mayer U, Steinmetz MO, Kammerer RA. 2006. Structure of the extracellular domain of Tie receptor tyrosine kinases and localization of the angiopoietin-binding epitope. J Biol Chem 281: 28408-28414.

Maisonpierre PC, Suri C, Jones PF, Bartunkova S, Wiegand SJ, Radziejewski C, Compton D, McClain J, Aldrich TH Papadopoulos N, et al. 1997. Angiopoietin-2, a natural antagonist for Tie2 that disrupts in vivo angiogenesis. Science 277: 55-60.

Marler KJ, Becker-Barroso E, Martinez A, Llovera M, Wentzel C, Poopalasundaram S, Hindges R, Soriano E, Comella J, Drescher U. 2008. A TrkB/EphrinA interaction controls retinal axon branching and synaptogenesis. $J$ Neurosci 28: 12700-12712.

Marston DJ, Dickinson S, Nobes CD. 2003. Rac-dependent trans-endocytosis of ephrinBs regulates Eph-ephrin contact repulsion. Nat Cell Biol 5: 879-888.

Master Z, Jones N, Tran J, Jones J, Kerbel RS, Dumont DJ. 2001. Dok-R plays a pivotal role in angiopoietin-1-dependent cell migration through recruitment and activation of Pak. EMBO J 20: 5919-5928.

Mendrola JM, Berger MB, King MC, Lemmon MA 2002. The single transmembrane domains of ErbB receptors self-associate in cell membranes. J Biol Chem 277: 4704-4712.

Mitra S, Duggineni S, Koolpe M, Zhu X, Huang Z, Pasquale EB. 2010. Structure-activity relationship analysis of peptides targeting the EphA2 receptor. Biochemistry 49: 6687-6695.

Moriki T, Maruyama H, Maruyama IN. 2001. Activation of preformed EGF receptor dimers by ligand-induced rotation of the transmembrane domain. J Mol Biol 311: 1011-1026.

Nievergall E, Janes PW, Stegmayer C, Vail ME, Haj FG, Teng SW, Neel BG, Bastiaens PI, Lackmann M. 2010. PTP1B regulates Eph receptor function and trafficking. J Cell Biol 191: $1189-1203$.

Niu XL, Peters KG, Kontos CD. 2002. Deletion of the carboxyl terminus of Tie 2 enhances kinase activity, signal- 
W.A. Barton et al.

ing, and function. Evidence for an autoinhibitory mechanism. J Biol Chem 277: 31768-31773.

Noberini R, Koolpe M, Peddibhotla S, Dahl R, Su Y, Cosford ND, Roth GP, Pasquale EB. 2008. Small molecules can selectively inhibit ephrin binding to the EphA4 and EphA2 receptors. J Biol Chem 283: 29461-29472.

Noberini R, Koolpe M, Lamberto I, Pasquale EB. 2012a. Inhibition of Eph receptor-ephrin ligand interaction by tea polyphenols. Pharmacol Rese 66: 363-373.

Noberini R, Lamberto I, Pasquale EB. 2012b. Targeting Eph receptors with peptides and small molecules: progress and challenges. Semin Cell Dev Biol 23: 51-57.

Noblitt LW, Bangari DS, Shukla S, Mohammed S, Mittal SK. 2005. Immunocompetent mouse model of breast cancer for preclinical testing of EphA2-targeted therapy. Cancer Gene Ther 12: 46-53.

Nowakowski J, Cronin CN, McRee DE, Knuth MW, Nelson CG, Pavletich NP, Rogers J, Sang BC, Scheibe DN, Swanson RV, et al. 2002. Structures of the cancer-related Aurora-A, FAK, and EphA2 protein kinases from nanovolume crystallography. Structure 10: 1659-1667.

Ottensmeyer FP, Beniac DR, Luo RZ, Yip CC. 2000. Mechanism of transmembrane signaling: Insulin binding and the insulin receptor. Biochemistry 39: 12103-12112.

Papapetropoulos A, Fulton D, Mahboubi K, Kalb RG O'Connor DS, Li F, Altieri DC, Sessa WC. 2000. Angiopoietin-1 inhibits endothelial cell apoptosis via the Akt/ survivin pathway. J Biol Chem 275: 9102-9105.

Pasquale EB. 2008. Eph-ephrin bidirectional signaling in physiology and disease. Cell 133: 38-52.

Pasquale EB. 2010. Eph receptors and ephrins in cancer: Bidirectional signalling and beyond. Nat Rev Cancer 10: 165-180.

Petty A, Myshkin E, Qin H, Guo H, Miao H, Tochtrop GP, Hsieh JT, Page P, Liu L, Lindner DJ, et al. 2012. A smal molecule agonist of EphA2 receptor tyrosine kinase inhibits tumor cell migration in vitro prostate cancer metastasis in vivo. PloS ONE 7: e42120.

Qin H, Shi J, Noberini R, Pasquale EB, Song J. 2008. Crystal structure and NMR binding reveal that two small molecule antagonists target the high affinity ephrin-binding channel of the EphA4 receptor. J Biol Chem 283: 29473-29484.

Qin H, Noberini R, Huan X, Shi J, Pasquale EB, Song J. 2010. Structural characterization of the EphA4-Ephrin-B2 complex reveals new features enabling Eph-ephrin binding promiscuity. J Biol Chem 285: 644-654.

Qin H, Lim L, Song J. 2012. Protein dynamics at Eph receptor-ligand interfaces as revealed by crystallography, NMR and MD simulations. BMC Biophys 5: 2 .

Ramsauer M, D'Amore PA. 2002. Getting Tie(2)d up in angiogenesis. J Clin Invest 110: 1615-1617.

Robinson D, He F, Pretlow T, Kung HJ. 1996. A tyrosine kinase profile of prostate carcinoma. Proc Natl Acad Sci 93: $5958-5962$.

Schlessinger J. 2003. Signal transduction. Autoinhibition control. Science 300: 750-752.

Seegar TC, Eller B, Tzvetkova-Robev D, Kolev MV, Henderson SC, Nikolov DB, Barton WA. 2010. Tie1-Tie2 interactions mediate functional differences between angiopoietin ligands. Mol Cell 37: 643-655.
Seiradake E, Harlos K, Sutton G, Aricescu AR, Jones EY. 2010. An extracellular steric seeding mechanism for Eph-ephrin signaling platform assembly. Nat Struct Mol Biol 17: 398-402.

Shewchuk LM, Hassell AM, Ellis B, Holmes WD, Davis R, Horne EL, Kadwell SH, McKee DD, Moore JT. 2000. Structure of the Tie2 RTK domain: Self-inhibition by the nucleotide binding loop, activation loop, and C-terminal tail. Structure 8: 1105-1113.

Shintani T, Ihara M, Sakuta H, Takahashi H, Watakabe I, Noda M. 2006. Eph receptors are negatively controlled by protein tyrosine phosphatase receptor type O. Nat Neurosci 9: 761-769.

Singla N, Himanen JP, Muir TW, Nikolov DB. 2008. Toward the semisynthesis of multidomain transmembrane receptors: Modification of Eph tyrosine kinases. Protein Sci 17: $1740-1747$.

Singla N, Erdjument-Bromage H, Himanen JP, Muir TW, Nikolov DB. 2011. A semisynthetic Eph receptor tyrosine kinase provides insight into ligand-induced kinase activation. Chem Biol 18: 361-371.

Sjoblom T, Jones S, Wood LD, Parsons DW, Lin J, Barber TD, Mandelker D, Leary RJ, Ptak J, Silliman N, et al. 2006. The consensus coding sequences of human breast and colorectal cancers. Science 314: 268-274.

Song J, Vranken W, Xu P, Gingras R, Noyce RS, Yu Z, Shen SH, Ni F. 2002. Solution structure and backbone dynamics of the functional cytoplasmic subdomain of human ephrin B2, a cell-surface ligand with bidirectional signaling properties. Biochemistry 41: 10942-10949.

Stamos J, Sliwkowski MX, Eigenbrot C. 2002. Structure of the epidermal growth factor receptor kinase domain alone and in complex with a 4 -anilinoquinazoline inhibitor. J Biol Chem 77: 46265-46272.

Sundberg EJ. 2009. Structural basis of antibody-antigen interactions. Methods Mol Biol 524: 23-36.

Valenzuela DM, Griffiths JA, Rojas J, Aldrich TH, Jones PF, Zhou H, McClain J, Copeland NG, Gilbert DJ, Jenkins NA, et al. 1999. Angiopoietins 3 and 4: Diverging gene counterparts in mice and humans. Proc Natl Acad Sci 96: 1904-1909.

Vearing C, Lee FT, Wimmer-Kleikamp S, Spirkoska V, To C, Stylianou C, Spanevello M, Brechbiel M, Boyd AW, Scott AM, et al. 2005. Concurrent binding of anti-EphA3 antibody and ephrin-A5 amplifies EphA3 signaling and downstream responses: Potential as EphA3-specific tumor-targeting reagents. Cancer Res 65: 6745-6754.

Volynsky PE, Mineeva EA, Goncharuk MV, Ermolyuk YS, Arseniev AS, Efremov RG. 2010. Computer simulations and modeling-assisted ToxR screening in deciphering 3D structures of transmembrane alpha-helical dimers: Ephrin receptor A1. Phys Biol 7: 16014.

Wang B. 2011. Cancer cells exploit the Eph-ephrin system to promote invasion and metastasis: Tales of unwitting partners. Sci Signal 4: e28.

Ward NL, Dumont DJ. 2002. The angiopoietins and Tie2/ Tek: Adding to the complexity of cardiovascular development. Semin Cell Dev Biol 13: 19-27.

Wiesmann C, Muller YA, de Vos AM. 2000. Ligand-binding sites in Ig-like domains of receptor tyrosine kinases. $J \mathrm{Mol}$ Med (Berl) 78: 247-260. 
Wiesner S, Wybenga-Groot LE, Warner N, Lin H, Pawson T, Forman-Kay JD, Sicheri F. 2006. A change in conformational dynamics underlies the activation of Eph receptor tyrosine kinases. EMBO J 25: 4686-4696.

Wimmer-Kleikamp SH, Janes PW, Squire A, Bastiaens PI, Lackmann M. 2004. Recruitment of Eph receptors into signaling clusters does not require ephrin contact. J Cell Biol 164: 661-666.

Wimmer-Kleikamp SH, Nievergall E, Gegenbauer K, Adikari S, Mansour M, Yeadon T, Boyd AW, Patani NR, Lackmann M. 2008. Elevated protein tyrosine phosphatase activity provokes Eph/ephrin-facilitated adhesion of pre-B leukemia cells. Blood 112: 721-732.
Wybenga-Groot LE, Baskin B, Ong SH, Tong J, Pawson T, Sicheri F. 2001. Structural basis for autoinhibition of the Ephb2 receptor tyrosine kinase by the unphosphorylated juxtamembrane region. Cell 106: $745-$ 757.

Yu X, Seegar TCM, Dalton AC, Tzvetkova-Robev D, Goldgur Y, Nikolov DB, Barton WA. 2013. Structural basis for angiopoietin-1 mediated signaling initiation. Proc Natl Acad Sci 110: 7205-7210.

Zimmer M, Palmer A, Kohler J, Klein R. 2003. EphB-ephrinB bi-directional endocytosis terminates adhesion allowing contact mediated repulsion. Nat Cell Biol 5: 869878 . 


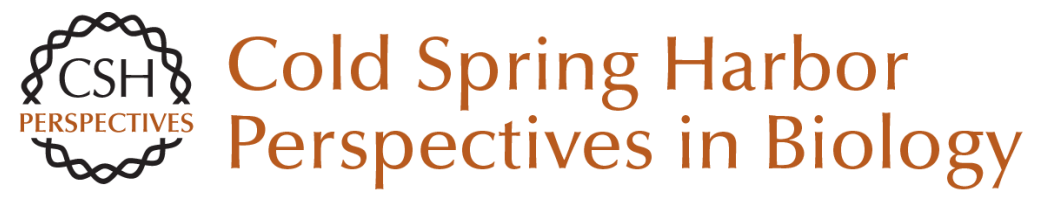

\section{Tie2 and Eph Receptor Tyrosine Kinase Activation and Signaling}

William A. Barton, Annamarie C. Dalton, Tom C.M. Seegar, Juha P. Himanen and Dimitar B. Nikolov

Cold Spring Harb Perspect Biol 2014; doi: 10.1101/cshperspect.a009142 originally published online January 29, 2014

\section{Subject Collection Signaling by Receptor Tyrosine Kinases}

CSF-1 Receptor Signaling in Myeloid Cells

E. Richard Stanley and Violeta Chitu

The EGFR Family: Not So Prototypical Receptor

Tyrosine Kinases

Mark A. Lemmon, Joseph Schlessinger and Kathryn M. Ferguson

Tie2 and Eph Receptor Tyrosine Kinase Activation and Signaling

William A. Barton, Annamarie C. Dalton, Tom C.M. Seegar, et al.

The Spatiotemporal Organization of ErbB Receptors: Insights from Microscopy

Christopher C. Valley, Keith A. Lidke and Diane S. Lidke

Insulin Receptor Signaling in Normal and Insulin-Resistant States

Jérémie Boucher, André Kleinridders and C. Ronald Kahn

Central Role of RET in Thyroid Cancer Massimo Santoro and Francesca Carlomagno

Receptor Tyrosine Kinase-Mediated Angiogenesis Michael Jeltsch, Veli-Matti Leppänen, Pipsa Saharinen, et al.
The Genesis of Tyrosine Phosphorylation Tony Hunter

Structure-Function Relationships of ErbB RTKs in the Plasma Membrane of Living Cells Donna J. Arndt-Jovin, Michelle G. Botelho and Thomas M. Jovin

Receptor Tyrosine Kinases: Legacy of the First

Two Decades Joseph Schlessinger

The Role of Ryk and Ror Receptor Tyrosine Kinases in Wnt Signal Transduction Jennifer Green, Roel Nusse and Renée van Amerongen

Regulation of Receptor Tyrosine Kinase Ligand Processing Colin Adrain and Matthew Freeman

Molecular Mechanisms of SH2- and PTB-Domain-Containing Proteins in Receptor Tyrosine Kinase Signaling Melany J. Wagner, Melissa M. Stacey, Bernard A. Liu, et al.

Eph Receptor Signaling and Ephrins Erika M. Lisabeth, Giulia Falivelli and Elena B. Pasquale

For additional articles in this collection, see http://cshperspectives.cshlp.org/cgi/collection/

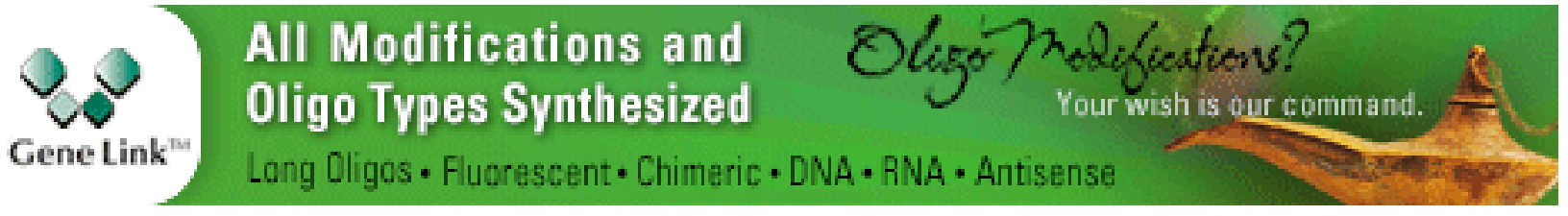




\section{Biology of the TAM Receptors \\ Greg Lemke}

Effects of Membrane Trafficking on Signaling by

Receptor Tyrosine Kinases

Marta Miaczynska

For additional articles in this collection, see http://cshperspectives.cshlp.org/cgi/collection/

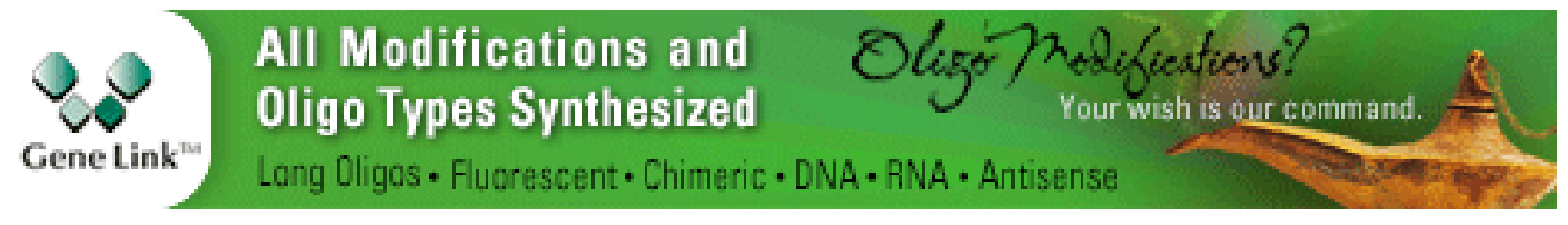

Copyright @ 2014 Cold Spring Harbor Laboratory Press; all rights reserved 